\title{
Dynamics and persistence of rabies in the Arctic
}

\author{
Audrey Simon ${ }^{1}$, Olivia Tardy ${ }^{1}$, Amy Hurford², Nicolas Lecomte ${ }^{3}$, Denise Bélanger ${ }^{1}$ \& Patrick A. Leighton ${ }^{1}$ \\ ${ }^{1}$ Research Group on Epidemiology of Zoonoses and Public Health, Faculty of Veterinary Medicine, University of Montreal, Quebec, Canada; \\ 2Department of Mathematics and Statistics, Memorial University of Newfoundland, St. John's, Newfoundland and Labrador, Canada; \\ ${ }^{3}$ Canada Research Chair in Polar and Boreal Ecology, Department of Biology, University of Moncton, Moncton, New Brunswick, Canada
}

\section{Abstract}

Rabies is a major issue for human and animal health in the Arctic, yet little is known about its epidemiology. In particular, there is an ongoing debate regarding how Arctic rabies persists in its primary reservoir host, the Arctic fox (Vulpes lagopus), which exists in the ecosystem at very low population densities. To shed light on the mechanisms of rabies persistence in the Arctic, we built a susceptible-exposed-infectious-recovered (SEIR) epidemiological model of rabies virus transmission in an Arctic fox population interacting with red foxes (Vulpes vulpes), a rabies host that is increasingly present in the Arctic. The model suggests that rabies cannot be maintained in resource-poor areas of the Arctic, characterized by low Arctic fox density, even in the presence of continuous reintroduction of the virus by infected Arctic foxes from neighbouring regions. However, in populations of relatively high Arctic fox density, rabies persists under conditions of higher transmission rate, prolonged infectious period and for a broad range of incubation periods. Introducing the strong cyclical dynamics of Arctic prey availability makes simulated rabies outbreaks less regular but more intense, with an onset that does not neatly track peaks in Arctic fox density. Finally, interaction between Arctic and red foxes increases the frequency and/or the intensity of rabies outbreaks in the Arctic fox population. Our work suggests that disruption of prey cycles and increasing interactions between Arctic and red foxes due to climate change and northern development may significantly change the epidemiology of rabies across the Arctic.
\end{abstract}

To access the supplementary material, please visit the article landing page

\section{Keywords}

Vulpes lagopus; epidemiological model; Arctic rabies; virus transmission; public health; climate change

\section{Correspondence}

Audrey Simon, Research Group on Epidemiology of Zoonoses and Public Health, 3200 Sicotte, Saint-Hyacinthe, J2S 2M2, Quebec, Canada.

E-mail: audrey.simon@umontreal.ca

\section{Abbreviations}

PRCC: partial rank correlation coefficient; SEIR: susceptible-exposed-infectiousrecovered (epidemiological model)

\section{Introduction}

Rabies is a zoonotic disease that represents a major worldwide health concern, with over 55000 human deaths annually (Knobel et al. 2005). Rabies virus is capable of infecting cerebral and nervous tissues of all mammals, usually leading to behavioural changes followed by death (WHO 2013). In the Arctic, rabies is endemic in wildlife, posing a significant and ongoing health concern for people and domestic animals living there (Mørk \& Prestrud 2004; Aenishaenslin et al. 2014). In the Canadian Arctic, rabies cases are reported each year in wildlife and domestic dogs, with periodic peaks in the number of cases (CFIA 2018). People are generally exposed to rabies virus when bitten by an infected wild carnivore or a domestic dog that became rabid following contact with infected wildlife (Mørk \& Prestrud 2004). The Arctic fox (Vulpes lagopus), with its circumpolar distribution, is considered to be the primary host species and reservoir for rabies throughout the Arctic (Mørk \& Prestrud 2004; Goldsmith et al. 2016). Although domestic dogs are an important rabies reservoir in many parts of the world, cases of Arctic fox strain rabies in dogs in the Arctic are generally associated with spillover from wildlife (Mørk \& Prestrud 2004). Early models of rabies dynamics in red foxes (Vulpes vulpes) in Europe suggest that a threshold density of 1.0 red fox per $\mathrm{km}^{2}$ is necessary to allow an epidemic to occur (Anderson et al. 1981). However, the greatest reported population density for Arctic foxes is only 0.3 foxes per $\mathrm{km}^{2}$ (Angerbjörn et al. 1999), raising 
the following question: what are the ecological and epidemiological features of the Arctic rabies system that allow rabies to persist given the exceptionally low density of its primary reservoir host?

Arctic fox abundance tends to follow a 3-4-year cycle, tracking the multi-annual population cycle of its primary prey, the lemming (Lemmus spp. and Dicrostonyx spp.), with increased juvenile recruitment during periods of high prey abundance (Elmhagen et al. 2000; Gilg et al. 2003; Krebs 2011). Rabies dynamics seem to parallel these fluctuations, suggesting a link between peak population densities of Arctic foxes and the onset of rabies epidemics (Elton 1931; Chapman 1978; Ritter 1981; Prestrud et al. 1992). In theory, rabies is more likely to persist at higher susceptible host densities (Lembo et al. 2008), but it is currently unclear what role cyclic fluctuations in densities of foxes might play in the dynamics and the persistence of rabies in the Arctic. In the literature, proposed mechanisms to explain rabies persistence in low-density Arctic fox populations are (1) prolonged incubation and/ or infectious periods, (2) reintroduction of rabies virus by immigrant infected Arctic foxes and (3) the presence of another reservoir for the virus, such as red foxes (Mørk \& Prestrud 2004).

High variation in the incubation period (eight days to six months) for rabies has been reported, but the infectious period is generally short, with rabid Arctic foxes usually dying within two days of the onset of symptoms (Konovalov et al. 1965; Rausch 1972). In addition, experimental infection studies have shown that a relatively high challenge dose of Arctic rabies virus is needed to induce $100 \%$ mortality in Arctic foxes compared to other canid species such as red foxes (Follmann et al. 1988; Follmann et al. 2004). When given a low challenge dose of rabies virus, some experimentally infected Arctic foxes failed to develop clinical disease (one out of three in Follmann et al. [1988] and Follmann et al. [2011] studies), suggesting either a particularly long incubation period in this species or a high innate resistance to infection by the Arctic rabies virus variant. Rabies antibodies were found in four of 99 trapped Arctic foxes in Alaska without detection of the virus (4\%) (Ballard et al. 2001). This suggests that some Arctic foxes can be exposed to rabies virus and survive, although it is not clear whether antibodies are a result of an aborted infection or recovery from an infection (Ballard et al. 2001; Prager et al. 2012). Finally, there is inadequate evidence to support the occurrence of asymptomatic carriers that can transmit the virus yet remain healthy, but the presence of immune Arctic foxes in the population could potentially lower the transmission rate and thus affect rabies persistence.

Movement of Arctic foxes is another potential factor explaining the persistence of rabies in the circumpolar
Arctic. According to the model developed by Tyul'ko and Kuzmin (2002), the maintenance of rabies in low carrying capacity biotopes such as the Arctic is possible only if the primary host species is highly mobile. An important characteristic of Arctic fox ecology is the ability of individuals to travel long distances, and this is especially true during winter movements (Audet et al. 2002). This tundra predator is also known to engage in sporadic longdistance forays during which individuals may travel outside of their usual home range (Audet et al. 2002; Lai et al. 2015; Simon et al. in press). When rabies virus is no longer circulating locally in the Arctic fox population, new rabies outbreaks could be triggered by the reintroduction of the virus following immigration of infected Arctic foxes from other areas (Mørk \& Prestrud 2004). The role of migrants in reintroducing rabies to regions where it has died out is also supported by genetic studies of the Arctic rabies virus variant that suggest disease spread by Arctic foxes travelling across the sea ice from Russia to Svalbard (Mørk et al. 2011) and from North America to Greenland (Mansfield et al. 2006).

The presence of other carnivore species as secondary reservoirs for the virus could also facilitate rabies persistence in the Arctic fox (Holmala \& Kauhala 2006). Over the last century, the red fox has expanded its range into the Arctic tundra, possibly because of increased food resources resulting from climate warming and/ or increased human development (Hersteinsson \& Macdonald 1992; Gallant et al. 2012). Arctic and red foxes compete for a similar ecological niche, leading to frequent aggressive interactions, including territorial fighting and predation (Pamperin et al. 2006) that may increase the chances of transmission of rabies virus between the two species. Furthermore, the high degree of genetic relatedness between rabies virus isolates from Arctic and red foxes suggests that rabies virus is easily transmitted between these species and widely dispersed over their combined ranges (Nadin-Davis et al. 2012). The increasing abundance of red foxes in the Arctic could therefore help ensure a baseline density of susceptible hosts, allowing rabies virus transmission to continue even when Arctic fox populations are low.

In this study, we built an epidemiological model to investigate the dynamics, the potential mechanisms and the necessary conditions for rabies persistence in a low-density Arctic fox population. We used the model to explore seven main hypotheses: (1) the mobility of Arctic foxes must be relatively high to allow rabies persistence; (2) multi-annual prey cycles exert a strong bottom-up effect on Arctic rabies dynamics through their effects on fox birth rate; (3) a prolonged incubation period increases rabies persistence; (4) a prolonged infectious period increases rabies persistence; (5) the 
existence of individuals with naturally acquired immunity increases the risk of rabies die-out by lowering the transmission potential; (6) immigration of infected Arctic foxes is a mechanism that allows rabies to continue circulating under conditions where the virus would not otherwise persist; and (7) the presence of sympatric red foxes increases rabies persistence in Arctic fox populations by increasing the overall density of susceptible individuals.

\section{Methods}

\section{Epidemiological model}

To model the dynamics of rabies and explore the conditions for persistence of rabies within low-density Arctic fox populations, we extended the deterministic compartmental model of Anderson et al. (1981) used to model rabies in European red foxes. This model assumes logistic growth, reproduction of disease-free Arctic foxes only and density-dependent transmission of the virus, which remains the most parsimonious mechanism by which stable epidemic cycles for rabies can be supported within deterministic random mixing models (Morters et al. 2013). The population of Arctic foxes $\left(N_{\mathrm{A}}\right)$ is divided into individuals that are susceptible (i.e., unexposed to rabies virus) $\left(S_{\mathrm{A}}\right)$, exposed to the virus but not yet infectious $\left(E_{\mathrm{A}}\right)$, infectious $\left(I_{\mathrm{A}}\right)$ and recovered from infection with lifelong immunity $\left(R_{\mathrm{A}}\right)$ (SEIR model). To explore our hypotheses regarding rabies dynamics and persistence in the Arctic, we modified the model of Anderson et al. (1981) by allowing (1) exposed Arctic foxes to become immune (i.e., aborting or surviving rabies infection), (2) rabies transmission between the Arctic foxes and sympatric red foxes, (3) periodicity in the birth rate of foxes resulting from prey cycles and (4) continuous immigration of infectious Arctic foxes from other regions.

We described the dynamics of rabies virus transmission in an Arctic fox population interacting with red foxes by the following first-order ordinary differential equations (Fig. 1):

$$
\begin{gathered}
\frac{d S_{\mathrm{A}}}{d t}=b_{A}(t) S_{\mathrm{A}}-\left[\mathrm{d}_{\mathrm{A}}+q_{\mathrm{A}}(t) N_{\mathrm{A}}\right] S_{\mathrm{A}}- \\
{\left[\beta_{\mathrm{A}} I_{\mathrm{A}}+\beta_{\mathrm{AR}} I_{\mathrm{R}}+\varphi_{\mathrm{A}}\right] S_{\mathrm{A}}+b_{\mathrm{A}}(t) R_{\mathrm{A}},} \\
\frac{d E_{\mathrm{A}}}{d t}=\left[\beta_{\mathrm{A}} I_{\mathrm{A}}+\beta_{\mathrm{AR}} I_{\mathrm{R}}+\varphi_{\mathrm{A}}\right] S_{\mathrm{A}}- \\
{\left[\mathrm{d}_{\mathrm{A}}+q_{\mathrm{A}}(t) N_{\mathrm{A}}\right] E_{\mathrm{A}}-\mu_{\mathrm{A}} E_{\mathrm{A}},}
\end{gathered}
$$

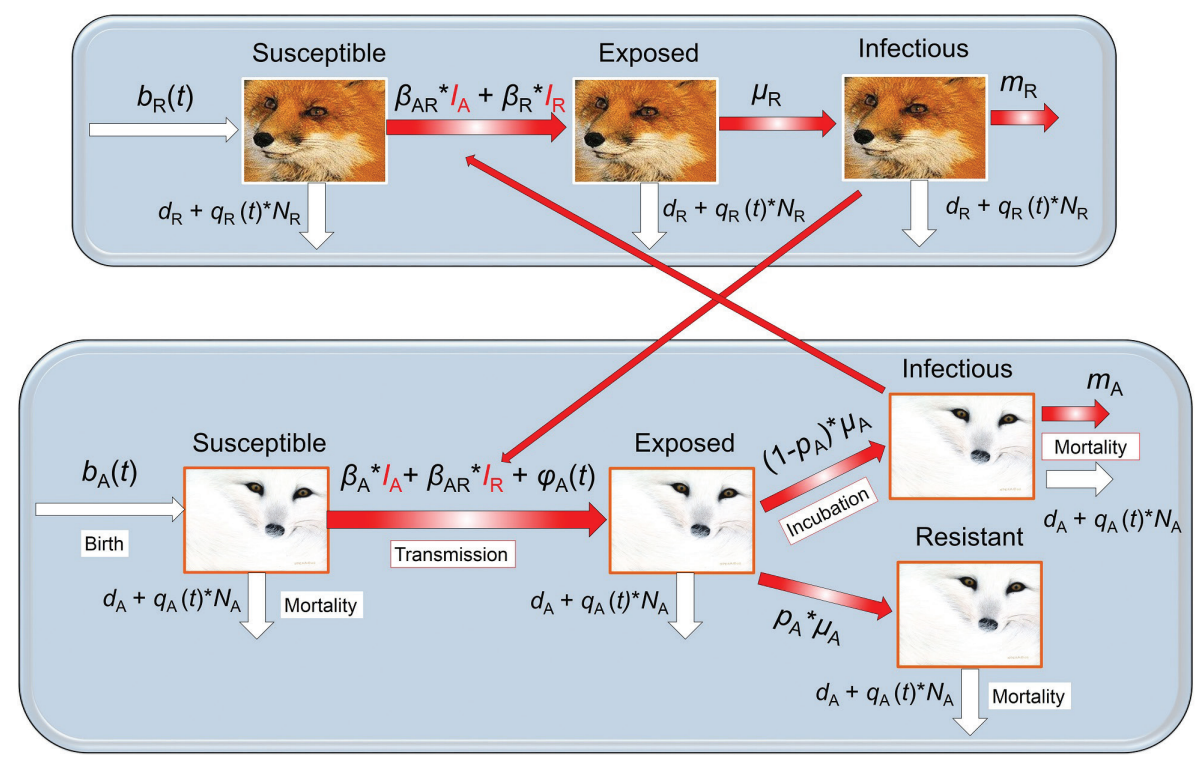

Fig. 1 A compartmental SEIR model simulating the transmission of rabies virus in a population of Arctic foxes (Vulpes lagopus) interacting with a sympatric population of red foxes (Vulpes vulpes), where ${ }_{A}$ and ${ }_{R}$ denote Arctic and red foxes, respectively. Rates of flow between the different compartments are represented by wide red and white arrows, describing the infectious and non-infectious processes, respectively. The red fox and Arctic fox models are connected through the infectious compartments (thin red arrows) with the transition between susceptible and exposed foxes depending on the number of infectious individuals of both fox species. The demographic and epidemiological parameters are the following: the average per capita density-independent birth rate $(b)$, the transmission coefficient $(\beta)$, the per capita rate of passage from the incubating state to the infectious state $(\mu)$, the death rate of rabid foxes $(m)$, the average per capita density-dependent death rate $(d)$, the intraspecific competition coefficient $(q)$ and the size of the fox population (N) (see Table 1 for details). 


$$
\begin{aligned}
& \frac{d I_{\mathrm{A}}}{d t}=\left(1-p_{\mathrm{A}}\right) \mu_{\mathrm{A}} E_{\mathrm{A}}-\left[\mathrm{d}_{\mathrm{A}}+q_{\mathrm{A}}(t) N_{\mathrm{A}}\right] I_{\mathrm{A}}-m_{\mathrm{A}} I_{\mathrm{A}}, \\
& \frac{d R_{\mathrm{A}}}{d t}=p_{\mathrm{A}} \mu_{\mathrm{A}} E_{\mathrm{A}}-\left[\mathrm{d}_{\mathrm{A}}+q_{\mathrm{A}}(t) N_{\mathrm{A}}\right] R_{\mathrm{A}}, \\
& \frac{d S_{\mathrm{R}}}{d t}=b_{\mathrm{R}}(t) S_{\mathrm{R}}-\left[\mathrm{d}_{\mathrm{R}}+q_{\mathrm{R}}(t) N_{\mathrm{R}}\right] S_{\mathrm{R}}-\left[\beta_{\mathrm{R}} I_{\mathrm{R}}+\beta_{\mathrm{AR}} I_{\mathrm{A}}\right] S_{\mathrm{R}}, \\
& \frac{d E_{\mathrm{R}}}{d t}=\left[\beta_{\mathrm{R}} I_{\mathrm{R}}+\beta_{\mathrm{AR}} I_{\mathrm{A}}\right] S_{\mathrm{R}}-\left[\mathrm{d}_{\mathrm{R}}+q_{\mathrm{R}}(t) N_{\mathrm{R}}\right] E_{\mathrm{R}}-\mu_{\mathrm{R}} E_{\mathrm{R}}, \\
& \frac{d I_{\mathrm{R}}}{d t}=\mu_{\mathrm{R}} E_{\mathrm{R}}-\left[\mathrm{d}_{\mathrm{R}}+q_{\mathrm{R}}(t) N_{\mathrm{R}}\right] I_{\mathrm{R}}-\mathrm{m}_{\mathrm{R}} I_{\mathrm{R}},
\end{aligned}
$$

where ${ }_{A}$ and ${ }_{R}$ denote the Arctic and red foxes, respectively. $N_{\mathrm{A}}$ represents the total density of Arctic foxes $\left(N_{\mathrm{A}}=S_{\mathrm{A}}+E_{\mathrm{A}}+R_{\mathrm{A}}+I_{\mathrm{A}}\right)$. We assumed that a proportion of exposed Arctic foxes $\left(p_{\mathrm{A}}\right)$ do not develop clinical signs and become immune to (or recover from) infection. The population of red foxes $\left(N_{\mathrm{R}}\right)$ is divided into the density of susceptible $\left(S_{\mathrm{R}}\right)$, exposed to the virus $\left(E_{\mathrm{R}}\right)$ and infectious $\left(I_{\mathrm{R}}\right)\left(N_{\mathrm{R}}=S_{\mathrm{R}}+E_{\mathrm{R}}+I_{\mathrm{R}}\right)$. Because red foxes may be susceptible to significantly lower doses of rabies virus than Arctic foxes (Follmann et al. 1988), we considered that no red foxes become immune to subsequent infection (the SEIR model then reduced to an SEI model). Transitions from the exposed $(E)$ to infectious $(I)$ disease classes and the mortality rate of infectious individuals are governed by the incubation $\left(1 / \mu_{\mathrm{A}}\right.$ and $\left.\left.1 / \mu_{\mathrm{R}}\right) 1\right)$ and infectious periods $\left(1 / m_{\mathrm{A}}\right.$ and $\left.1 / m_{\mathrm{R}}\right)$ for Arctic and red foxes, respectively. The rabies transmission coefficients for the Arctic and red foxes $\left(\beta_{\mathrm{A}}\right.$ and $\beta_{\mathrm{R}}$ ) take into account the contact rate between foxes and the probabilities of infection following contact. This parameter is inherently linked to animal movement and social behaviour.

We modelled virus transmission between the Arctic and red fox populations by connecting the Arctic fox model with a red fox model through the infectious (I) compartments. We included a parameter for the interspecific transmission rate, $\beta_{\mathrm{AR}^{\prime}}$ defined as the mean of the within-species transmission coefficients modified by $C_{\mathrm{AR}^{\prime}}$ the strength of interaction between Arctic and red foxes, where $C_{\mathrm{AR}}$ ranges between 0 and 1 (Dobson 2004). The rate of transmission between Arctic and red foxes was thus given by the following equation:

$$
\beta_{\mathrm{AR}}=c_{\mathrm{AR}}\left(\frac{\beta_{\mathrm{A}}+\beta_{\mathrm{R}}}{2}\right)
$$

The parameter $b(t)$ represents the birth rate and $\mathrm{d}$ represents the natural mortality rate. Density-dependent effects on natural mortality occurred at rate $q(t) N$, where $q(t)$ is the intraspecific competition coefficient given by $\frac{b(t)-d}{K}$, where $K$ represents the carrying capacity of the environment. We modelled prey-driven periodicity in the birth rate of Arctic foxes and red foxes $\left(b_{\mathrm{A}}\right.$ and $\left.b_{\mathrm{R}}\right)$ as sinusoidal functions of time $t$, using approaches proposed by Altizer et al. (2006) for incorporating periodicity into epidemiological models:

$$
b(t)=b_{0}\left(1+T b_{0} \cos (1 / 2 \pi t)\right) .
$$

The parameter $T b_{0}$ affects the range of birth rates attained by foxes during the cycle (i.e., birth rates range from $b_{0}\left(1-T b_{0}\right)$ to $\left.b_{0}\left(1+T b_{0}\right)\right)$. We also included preydriven periodicities in the red fox population birth rate because in regions where lemming cycles prevail, red foxes can also exhibit population cycles that mirror the cycle of their rodent prey (Henden et al. 2010).

Similarly to Blackwood et al. (2013), we included an immigration parameter, $\varphi_{\mathrm{A}^{\prime}}$ that contributes to the force of infection (i.e., the risk that a susceptible individual becomes infectious after exposure to a pathogen) in our model. This parameter can be interpreted as the exposure rate from immigrant rabid Arctic foxes that may enter the population year-round. The values of $\varphi_{\mathrm{A}}$ were set to 0.001-0.01 rabid Arctic foxes/yr. Immigration of infectious red foxes was not included in our model given that they are not known to carry out the same type of long-distance winter movements that are well documented in Arctic foxes (Audet et al. 2002; Lai et al. 2015).

Table 1 gives a detailed description and values of all ecological and epidemiological parameters included in the model, which were derived from the literature (see Supplementary Table S1 for details). In absence of data on the transmission coefficient $\beta$, which is the most difficult parameter to estimate in any host-pathogen model (McCallum et al. 2001), we tested a range of likely $\beta$ values (30-400 $\mathrm{km}^{2} / \mathrm{fox} / \mathrm{yr}$ ) based on previous modelling studies (Tyul'ko \& Kuzmin 2002; Bolzoni et al. 2008). We ran the model for 300 years to ensure that the system reached a stable equilibrium. We implemented the model in $\mathrm{R}$ version 3.4.2 (R Core Team 2017) and the system of ordinary differential equations was numerically solved using the lsoda solver in the package "deSolve" (Soetaert et al. 2010).

\section{Parameters influencing the persistence and dynamics of rabies}

We performed model simulations to test different hypotheses regarding the mechanisms underlying rabies dynamics and persistence in the Arctic. 
Table 1 Description, values and ranges of demographic and epidemiological parameters under the SEIR model of Arctic rabies dynamics (see Supplementary Table $\mathrm{S} 1$ for the details of parameter values derived from the literature).

\begin{tabular}{|c|c|c|c|c|c|}
\hline Symbol & Description (unit) & $\begin{array}{l}\text { Values explored for the } \\
\text { sensitivity analysis }\end{array}$ & $\begin{array}{l}\text { Values explored for } \\
\text { the baseline scenario }\end{array}$ & $\begin{array}{l}\text { Values explored for } \\
\text { the interactions }\end{array}$ & References \\
\hline \multicolumn{6}{|c|}{$\overline{\text { Arctic fox }}$} \\
\hline$b_{A 0}$ & Birth rate of Arctic foxes (1/yr) & 0.9 & 0.9 & 0.9 & Shirley et al. 2009 \\
\hline$T b_{\mathrm{AO}}$ & $\begin{array}{l}\text { Magnitude of periodicity in the birth } \\
\text { rate of Arctic foxes }\end{array}$ & $0-0.9^{a}$ & 0 & $0 ; 0.1 ; 0.9$ & \\
\hline$d_{A}$ & $\begin{array}{l}\text { Natural mortality rate of Arctic foxes } \\
(1 / y r)\end{array}$ & 0.5 & 0.5 & 0.5 & Shirley et al. 2009 \\
\hline$K_{\mathrm{A}}$ & Carrying capacity of Arctic foxes $\left(1 / \mathrm{km}^{2}\right)$ & $0.02-0.3$ & $0.02 ; 0.15 ; 0.3$ & $0.02 ; 0.15 ; 0.3$ & Angerbjörn et al. 1999 \\
\hline$\varphi_{\mathrm{A}}$ & $\begin{array}{l}\text { Immigration rate of infectious Arctic } \\
\text { foxes (foxes/yr) }\end{array}$ & $0-0.01$ & 0 & $0 ; 0.001 ; 0.01$ & Blackwood et al. 2013 \\
\hline$\beta_{\mathrm{A}}$ & $\begin{array}{l}\text { Transmission rate for rabies within } \\
\text { Arctic fox populations (km²/fox/yr) }\end{array}$ & $30-400$ & $290 ; 350 ; 400$ & 390 & Tyul'ko \& Kuzmin 2002 \\
\hline$p_{\mathrm{A}}$ & Proportion of immune Arctic foxes & $0-0.1$ & 0 & 0 & Ballard et al. 2001 \\
\hline$\mu_{\mathrm{A}}$ & $\begin{array}{l}\text { Rate at which exposed Arctic foxes } \\
\text { become infectious (1/yr) }\end{array}$ & $2-37$ & 15 & 37 & $\begin{array}{l}\text { Konovalov et al. 1965; } \\
\text { Rausch } 1972\end{array}$ \\
\hline$m_{\mathrm{A}}$ & $\begin{array}{l}\text { Disease-induced mortality rate of } \\
\text { Arctic foxes (1/yr) }\end{array}$ & $73-365$ & $73^{b}$ & 73 & $\begin{array}{l}\text { Konovalov et al. 1965; } \\
\text { Rausch 1972; Anderson et al. } \\
\text { 1981; Tyul'ko \& Kuzmin } 2002\end{array}$ \\
\hline \multicolumn{6}{|l|}{ Red fox } \\
\hline$b_{\text {RO }}$ & Birth rate of red foxes $(1 / y r)$ & 0.6 & 0.6 & 0.6 & Shirley et al. 2009 \\
\hline$T b_{\mathrm{RO}}$ & $\begin{array}{l}\text { Degree of periodicity in the birth rate } \\
\text { of red foxes }\end{array}$ & $0-0.4^{a}$ & 0 & $0 ; 0.1 ; 0.4$ & \\
\hline$d_{R}$ & Natural mortality rate of red foxes (1/yr) & 0.5 & 0.5 & 0.5 & Shirley et al. 2009 \\
\hline$K_{\mathrm{R}}$ & Carrying capacity of red foxes $\left(1 / \mathrm{km}^{2}\right)$ & $0.01-0.2$ & $0.01 ; 0.2$ & $0.01 ; 0.2$ & $\begin{array}{l}\text { Angerbjörn et al. 1999; Hol- } \\
\text { mala \& Kauhala } 2006\end{array}$ \\
\hline$\beta_{\mathrm{R}}$ & $\begin{array}{l}\text { Rate of rabies transmission within red } \\
\text { fox populations }\left(\mathrm{km}^{2} / \mathrm{fox} / \mathrm{yr}\right)\end{array}$ & $30-400$ & $290 ; 350 ; 400$ & 390 & Tyul'ko \& Kuzmin 2002 \\
\hline$\mu_{R}$ & $\begin{array}{l}\text { Rate at which exposed red foxes } \\
\text { become infectious (1/yr) }\end{array}$ & 13 & 13 & 13 & $\begin{array}{l}\text { Anderson et al. 1981; } \\
\text { Tyul'ko \& Kuzmin } 2002\end{array}$ \\
\hline$m_{R}$ & $\begin{array}{l}\text { Disease-induced mortality rate of red } \\
\text { foxes (1/yr) }\end{array}$ & 73 & 73 & 73 & $\begin{array}{l}\text { Anderson et al. 1981; } \\
\text { Tyul'ko \& Kuzmin } 2002\end{array}$ \\
\hline$C_{A R}$ & $\begin{array}{l}\text { Strength of transmission rate } \\
\text { between Arctic and red foxes }\end{array}$ & $0-0.1$ & 0 & $0 ; 0.01 ; 0.1$ & \\
\hline
\end{tabular}

${ }^{a}$ Calculated for an average per capita birth rate varying according to values in the crash and peak periods of the fox population cycles (see Supplementary Table S1). ${ }^{b}$ Given rabies did not persist at an average value of disease-induced mortality rate, we chose a value allowing rabies to persist (see Supplementary Table S1, Supplementary Note).

Firstly, we conducted a global sensitivity analysis using the Latin hypercube sampling method with a partial rank correlation coefficient (PRCC) index (Blower \& Dowlatabadi 1994; Marino et al. 2008) to identify the most influential parameters. We considered the cumulative density of rabies cases occurring during a simulation experiment (or cumulative incidence) as the model output of interest. Cumulative incidence has the advantage of capturing the effects of model parameters on both the persistence of rabies (as evidenced by a positive accumulation of cases over time) and the overall impact of recurrent rabies outbreaks on the population over time (greater or lesser total accumulation). Given that field data from Arctic ecosystems were insufficient to unambiguously determine the probability distribution for each parameter, we assumed a uniform probability distribution across the ranges listed in Table 1 (see the third column). The use of the uniform distribution ensures that all values within the allowed range are sampled with the same probability (Shirley et al. 2009). We solved the epidemiological model numerically using a broad set $(n=1000)$ of sampled parameter values and calculated PRCCs between the cumulative density of rabies cases and each varying parameter using 1000 bootstrap replicates. PRCC values 
vary between -1 and 1 , with values close to 1 indicating that the parameter has a strong positive correlation with the output variable, values close to -1 indicating a strong negative correlation with the output variable and values near 0 suggesting little effect. Because previous studies emphasized the importance of exploring the temporal variation of the sensitivity of the model output of interest to parameters when the time effect is unknown (Marino et al. 2008; Wu et al. 2013), we also sampled the density of infectious Arctic foxes $I_{\mathrm{A}}$ at each time step and plotted PRCCs over the time. We performed all analyses using the R package "lhs" and "sensitivity" (Carnell 2012; Pujol et al. 2017).

Secondly, we used heat maps to carry out exploratory analyses to identify the range of conditions that allowed for the persistence of the infectious class (i.e., $\frac{d I_{A}}{d t}>0$ ) by varying the values of specific parameters across the range listed in Table 1 (see the third column). We set all other parameters to their baseline value (see Table 1, fourth column).

Finally, under the previously defined conditions for rabies persistence, we tested the interacting effects of model parameters on the frequency and intensity of rabies outbreaks by running simulations with three values of each parameter of interest, while setting all other parameters to values allowing rabies persistence (see Table 1, fifth column).

\section{Results}

\section{Sensitivity analyses}

The carrying capacity of Arctic foxes $\left(K_{\mathrm{A}}\right)$ and the rate of rabies virus transmission within the population of Arctic foxes $\left(\beta_{\mathrm{A}}\right)$ showed strong positive correlations with the cumulative density of rabies cases (PRCCs > 0.7; Fig. 2). The immigration rate of infectious Arctic foxes entering the population $\left(\varphi_{\mathrm{A}}\right)(\mathrm{PRCC}=0.54)$, and the rate at which exposed Arctic foxes become infectious $\left(\mu_{\mathrm{A}}\right)$ $(\mathrm{PRCC}=0.22)$, corresponding to a negative correlation with the incubation period, showed more moderate positive correlations. A strong negative correlation was observed between the rabies-induced mortality rate of Arctic foxes $\left(m_{\mathrm{A}}\right)$ and the cumulative density of rabies cases (PRCC $=-0.75)$, corresponding to a positive correlation with the infectious period. The proportion of immune Arctic foxes $\left(p_{\mathrm{A}}\right)$ and the strength of the transmission rate between Arctic and red foxes $\left(C_{\mathrm{AR}}\right)$ showed weak negative correlations with the cumulative density of rabies cases (PRCCs $<-0.2$ ). PRCC values for other parameters did not differ significantly from zero (95\% confidence intervals

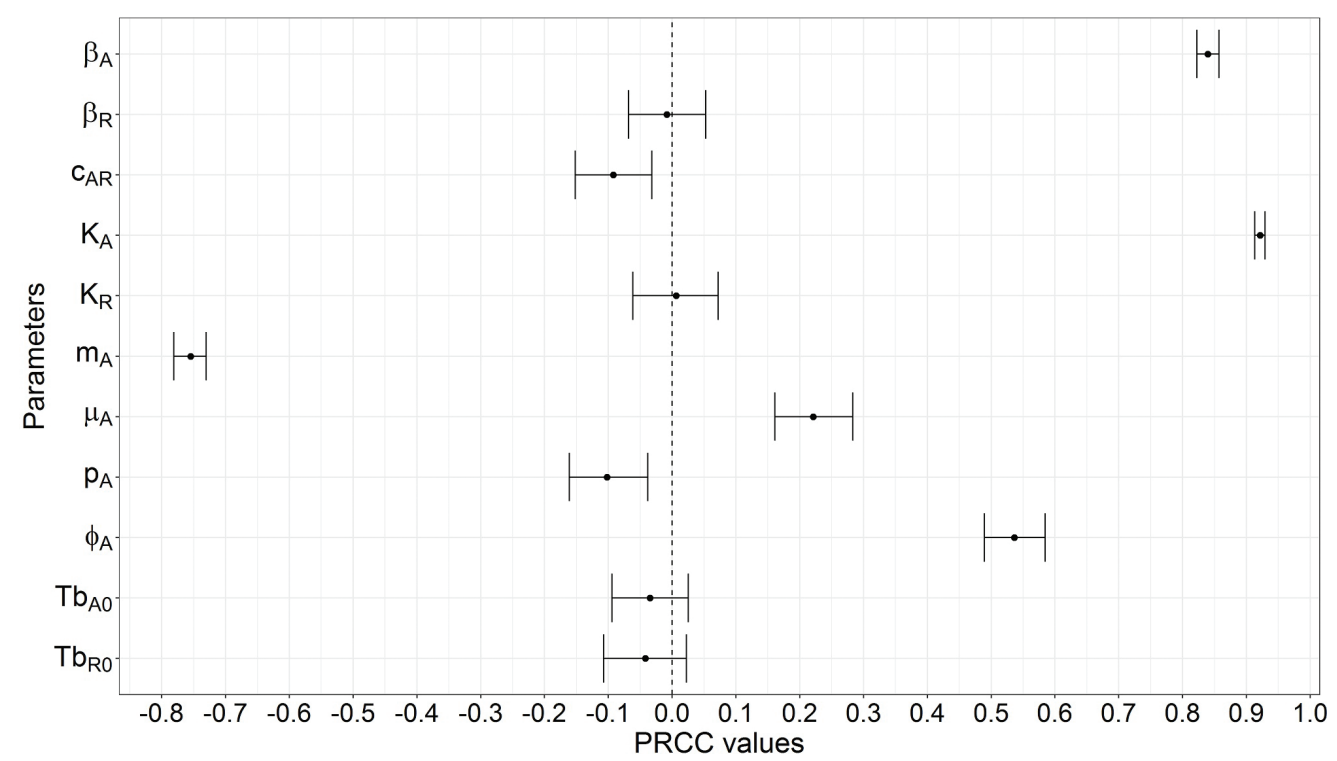

Fig. 2 PRCCs that characterize the association between the cumulative density of new rabies cases in the population of Arctic foxes over time and each input parameter of the epidemiological model. We calculated the PRCCs from 1000 bootstrap replicates and the input parameters were sampled using the Latin hypercube sampling method. Values close to 1 indicate a strong positive correlation between the parameter and the cumulative density of new rabies cases, whereas values close to -1 indicate a strong negative correlation and values whose $95 \%$ confidence interval (error bars) overlaps with zero are not significantly correlated with cumulative rabies cases. 
including zero). The correlations found in this analysis were consistent with the results of the sensitivity analysis through the time (see Supplementary Fig. S1).

\section{Rabies persistence}

We used exploratory analyses to identify the conditions allowing the persistence of rabies in the Arctic fox population for several key parameters (see Supplementary Note). We found that rabies did not persist in the Arctic fox population for both $\mathrm{K}_{\mathrm{A}}=0.15$ Arctic foxes $/ \mathrm{km}^{2}$ and $\mathrm{K}_{\mathrm{A}}=0.02$ Arctic foxes $/ \mathrm{km}^{2}$, for all values of other parameters tested. However, rabies persisted at $\mathrm{K}_{\mathrm{A}}=0.3$ Arctic foxes $/ \mathrm{km}^{2}$ under conditions of relatively high transmission rate $\left(\beta_{\mathrm{A}}>285 \mathrm{~km}^{2} /\right.$ fox $\left./ \mathrm{yr}\right)$, prolonged infectious periods $\left(1 / m_{\mathrm{A}}>3\right.$ days $)$ and for a large range of incubation periods ( 10 days $<1 / \mu_{\mathrm{A}}>182$ days). However, rabies did not persist at long incubation periods when transmission rate was low $\left(1 / \mu_{\mathrm{A}}>73\right.$ days for $\beta_{\mathrm{A}}=290 \mathrm{~km}^{2} /$ fox $\left./ \mathrm{yr}\right)$. The proportion of immune Arctic foxes, the immigration of infectious Arctic foxes and the presence of red foxes had little or no clear effect on rabies persistence.

\section{Rabies dynamics under conditions of persistence}

Restricting parameter set to the conditions allowing rabies persistence, we explored the interacting effects of carrying capacity, multi-annual prey cycles, immigration and the presence of red foxes on rabies dynamics.

Carrying capacity. At $\mathrm{K}_{\mathrm{A}}=0.3$ Arctic foxes $/ \mathrm{km}^{2}$, introducing rabies into a non-cyclic Arctic fox population caused damped oscillations stabilizing this population around 0.2 Arctic foxes $/ \mathrm{km}^{2}$ (Fig. 3a). However, without immigration of infectious Arctic foxes and in the absence of red foxes, rabies went extinct in the Arctic fox population for both $\mathrm{K}_{\mathrm{A}}=0.15$ Arctic foxes $/ \mathrm{km}^{2}$ and $\mathrm{K}_{\mathrm{A}}=0.02$ Arctic foxes $/ \mathrm{km}^{2}$, for all values of the other parameters tested (see Supplementary Fig. S9).

Multi-annual prey cycles. A small degree of periodicity in birth rate $\left(\mathrm{TbA}_{0}=0.1\right)$, due to the variation in the availability of food resources, transformed the enzootic equilibrium of the unforced model into an epizootic four-year cycle (Fig. 3b). Increasing birth rate periodicity to $\mathrm{TbA}_{0}=0.9$ caused epizootics to become more intense and more irregular, with high-amplitude fluctuations in density of infectious Arctic foxes, and periodicity in rabies outbreaks ranging from two to 11 years $($ median $=$ six years $)($ Fig. $3 \mathrm{c})$. Under these conditions of strong multi-annual forcing, the onset of rabies epizootics did not neatly track peaks in Arctic fox density (Fig. 3c).

Immigration of infectious Arctic foxes. At $\mathrm{K}_{\mathrm{A}}=0.15$ Arctic foxes $/ \mathrm{km}^{2}$ and $\mathrm{K}_{\mathrm{A}}=0.02$ Arctic foxes $/ \mathrm{km}^{2}$, even relatively high values of immigration rate of infectious Arctic foxes did not cause rabies to persist (see Supplementary Fig. S9). At these densities, sporadic rabies outbreaks occurred but died out rapidly with negligible values of density of infectious Arctic foxes $\left(0\right.$ to $10^{-6}$ infectious Arctic foxes $/ \mathrm{km}^{2}$ corresponding to a maximal prevalence of $0.005 \%$ ). At $\mathrm{K}_{\mathrm{A}}=0.3$ Arctic foxes $/ \mathrm{km}^{2}$, the annual immigration of infectious Arctic foxes only had an effect when a strong periodicity in prey availability was

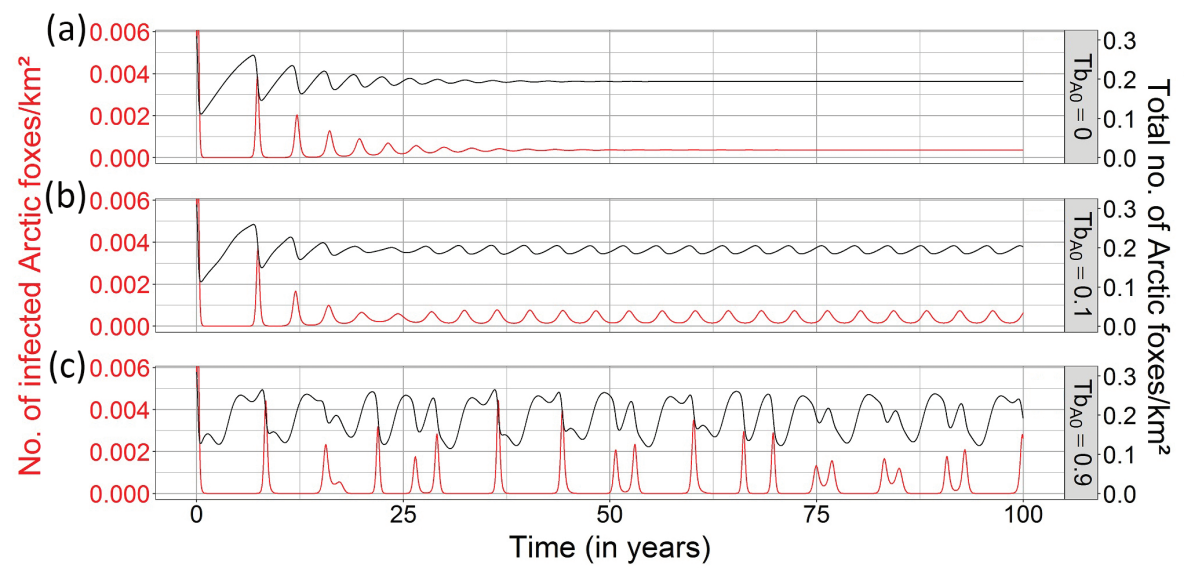

Fig. 3 Effects of periodicity in food availability on the dynamics of rabies in an Arctic fox population $\left(\mathrm{K}_{\mathrm{A}}=0.3 \mathrm{Arctic}\right.$ foxes/km²) when red foxes are absent in the system. Three values of periodicity in Arctic fox birth rate were tested: (a) $\mathrm{Tb}_{\mathrm{A0}}=0$, (b) $\left.\mathrm{Tb}_{\mathrm{A0}}=0.1 \mathrm{and}(\mathrm{c}) \mathrm{Tb}_{\mathrm{A0}}=0.9\right)$. The black and red lines show the total number of Arctic foxes per $\mathrm{km}^{2}\left(N_{A}\right)$ and the number of infectious Arctic foxes per km² $\left(I_{A}\right)$, respectively. The parameter associated with the immigration rate of infectious Arctic foxes $\left(\phi_{A}\right)$ was equal to zero, while all other parameters were fixed to the values mentioned in Table 1 (see the fourth column). 
included $\left(\mathrm{TbA}_{0}=0.9\right)$, with frequency and intensity of rabies outbreaks becoming more regular as immigration rate increased (Fig. 4).

Presence of red foxes. At low and medium Arctic fox carrying capacities $\left(K_{A}=0.02\right.$ Arctic foxes $/ \mathrm{km}^{2}$ and $\mathrm{K}_{\mathrm{A}}=0.15$ Arctic foxes $/ \mathrm{km}^{2}$ ), even a high red fox carrying capacity $\left(\mathrm{K}_{\mathrm{R}}=0.2 \mathrm{red}\right.$ foxes $\left./ \mathrm{km}^{2}\right)$ did not allow rabies to persist (see Supplementary Figs. S10, S11). Under conditions of high Arctic fox carrying capacity $\left(\mathrm{K}_{\mathrm{A}}=0.3\right.$ Arctic foxes $\left./ \mathrm{km}^{2}\right)$, the presence of red foxes at carrying capacities that were lower than $\left(\mathrm{K}_{\mathrm{R}}=0.01\right.$ red foxes $\left./ \mathrm{km}^{2}\right)$ or similar to $\left(\mathrm{K}_{\mathrm{R}}=0.2\right.$ red foxes $\left./ \mathrm{km}^{2}\right)$ those of Arctic foxes did not seem to have an impact on rabies dynamics in a non-cyclic Arctic fox population, compared to rabies dynamics in the absence of red foxes (see Supplementary Figs. S12a, d, S13a, d). However, when both Arctic and red fox populations were under strong forcing from multi-annual prey cycles $\left(\mathrm{Tb}_{\mathrm{A} 0}=\right.$ 0.9 , and $\left.\mathrm{Tb}_{\mathrm{R} 0}=0.4\right)$, frequency and intensity of rabies outbreaks were modified (Fig. 5). Under conditions of high Arctic fox carrying capacity $\left(\mathrm{K}_{\mathrm{A}}=0.3\right.$ Arctic foxes/ $\left.\mathrm{km}^{2}\right)$ and low red fox carrying capacity $\left(\mathrm{K}_{\mathrm{R}}=0.01 \mathrm{red}\right.$ foxes $/ \mathrm{km}^{2}$ ), only a strong interspecies rabies transmission rate $\left(C_{\mathrm{AR}}=0.1\right)$ transformed the irregular pattern of outbreaks seen in the absence of red foxes (Fig. 3c) into a regular eight-year-cycle rabies dynamics in the Arctic fox population (Fig. 5a). The peaks in infectious individuals during rabies outbreaks became higher (Fig. 5a). When carrying capacities of Arctic and red foxes were similar $\left(\mathrm{K}_{\mathrm{A}}=0.3\right.$ Arctic foxes $/ \mathrm{km}^{2}$ and $\mathrm{K}_{\mathrm{R}}=0.2$ red foxes $/ \mathrm{km}^{2}$ ) and highly cyclic, even a low interspecies transmission rate of rabies $\left(C_{\mathrm{AR}}=0.01\right)$ transformed the irregular pattern of outbreaks seen in the absence of red foxes into a regular four-year cycle with epizootics
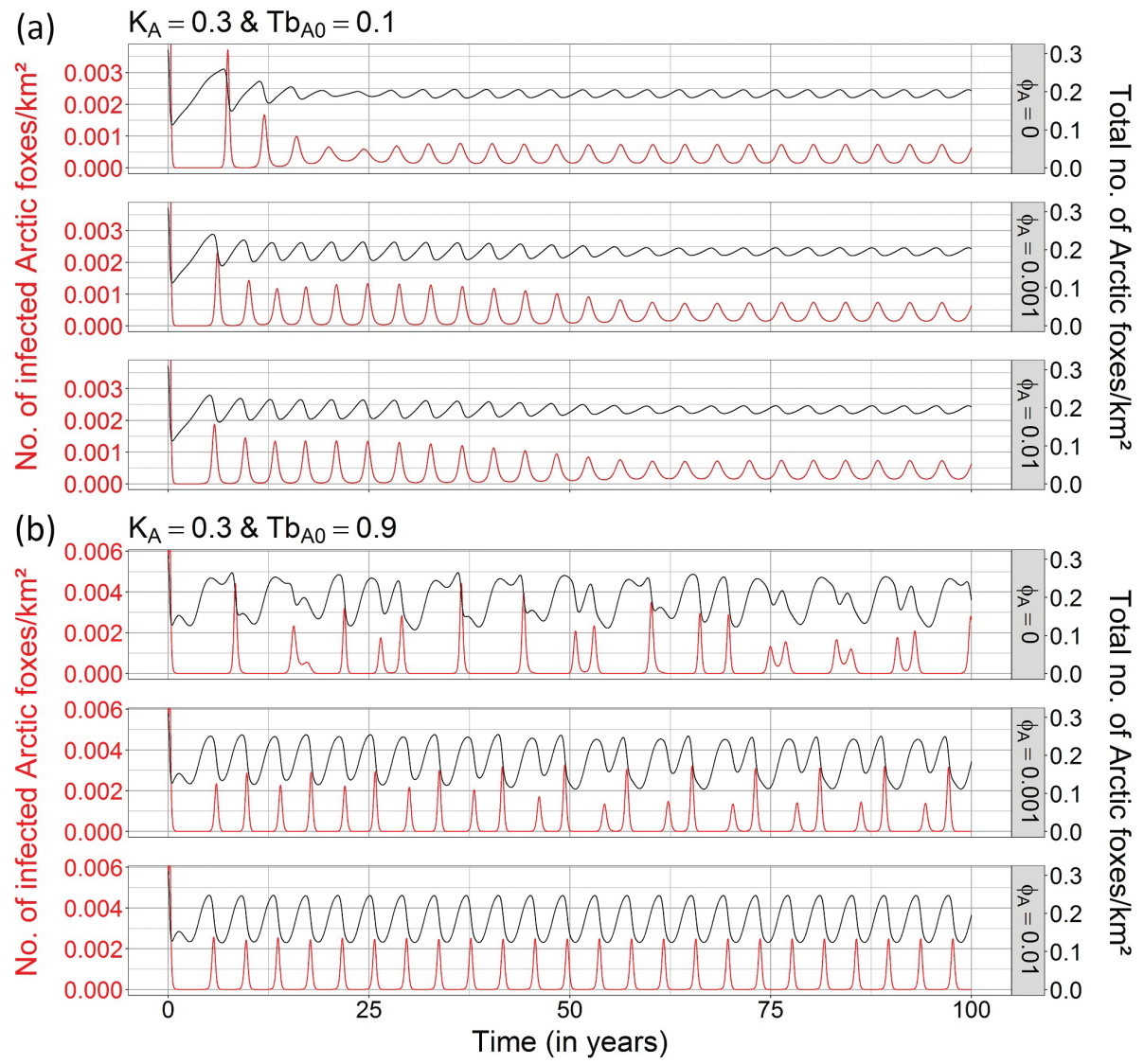

Fig. 4 Effects of both immigration of infectious Arctic foxes and periodicity in food availability on the dynamics of rabies in an Arctic fox population when red foxes are absent in the system. Three values of the immigration rate of infectious Arctic foxes (Arctic foxes/yr) were tested $\left(\phi_{\mathrm{A}}=0\right.$; $\phi_{\mathrm{A}}=0.001$; $\left.\phi_{A}=0.01\right)$. The black and red lines show the total number of Arctic foxes per $\mathrm{km}^{2}\left(N_{A}\right)$ and the number of infectious Arctic foxes per km $\left(I_{A}\right)$, respectively. The two panels $(a, b)$ are examples for combinations of one level of carrying capacity of Arctic foxes $\left(K_{A}=0.3\right.$ Arctic foxes/km²), and two levels of the magnitude of periodicity in the birth rate of Arctic foxes $\left(\mathrm{Tb}_{\mathrm{AO}}\right)$ : (a) weak periodicity $\left(\mathrm{Tb}_{\mathrm{AO}}=0.1\right)$ and $(\mathrm{b})$ strong periodicity $\left(\mathrm{Tb} \mathrm{A}_{\mathrm{A}}=0.9\right)$. $\mathrm{All}$ other parameters were fixed to the values mentioned in Table 1 (see the fourth column). 

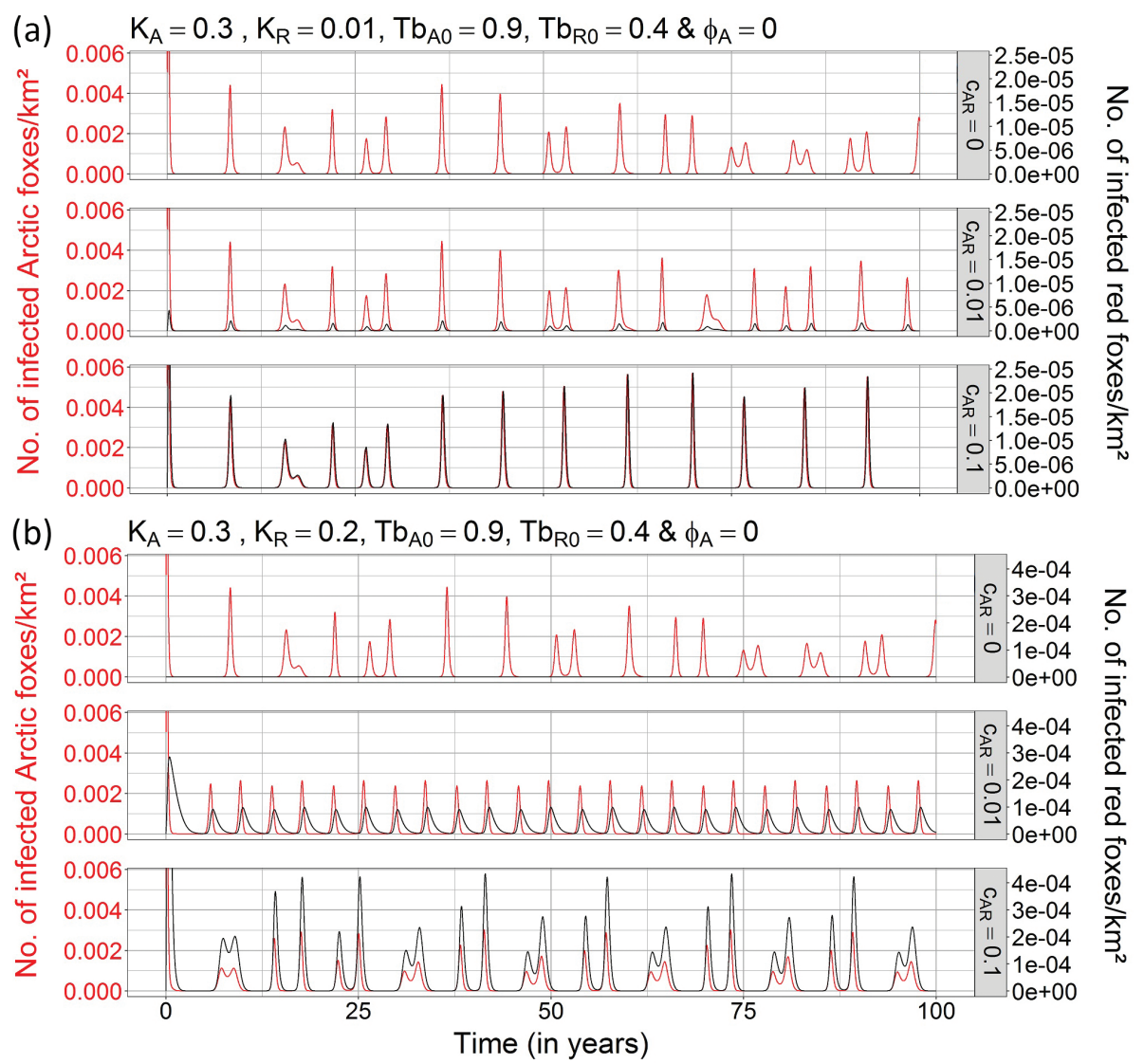

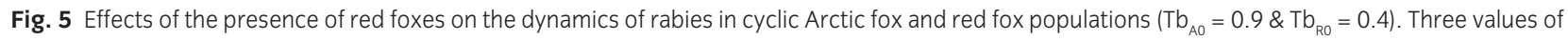
the strength of the transmission rate between Arctic and red foxes were tested $\left(C_{A R}=0 ; C_{A R}=0.01 ; C_{A R}=0.1\right)$. The black and red lines show the number of infectious red foxes per $\mathrm{km}^{2}\left(I_{R}\right)$ and the number of infectious Arctic foxes per $\mathrm{km}^{2}\left(I_{A}\right)$, respectively. The two panels $(a$, b) illustrate the dynamics of interaction when red fox carrying capacity is (a) low $\left(K_{R}=0.01\right.$ foxes $\left./ \mathrm{km}^{2}\right)$ and (b) high $\left(K_{R}=0.2\right.$ foxes $\left./ \mathrm{km}^{2}\right)$. The rate of immigrating infectious Arctic foxes $\left(\phi_{A}\right)$ was set to zero, while all other parameters were fixed to the values mentioned in Table 1 (see the fourth column).

of lower intensity (Fig. 5b). The intensity of rabies outbreaks became higher and less regular as the interspecies transmission rate of rabies increased $\left(C_{\mathrm{AR}}=0.1\right)$ (Fig. $5 b)$. Peaks in rabies epizootics in red foxes invariably followed those in Arctic foxes, with epizootics increasingly synchronized as the interspecies transmission rate of rabies increased (Fig. 5b).

\section{Discussion}

This work represents the first model of rabies dynamics in the Arctic, a valuable step in risk assessment for rabies in northern regions, particularly in light of important climatic and anthropogenic changes occurring in arctic ecosystems. We adapted and extended a deterministic model that has been successful in capturing the main features and observed epidemiological trends in fox rabies worldwide (Anderson et al. 1981).
We incorporated multi-annual prey cycles, a prolonged incubation and infectious period, recovery and immunity of Arctic foxes, immigration of infectious individuals and interactions with a sympatric rabies host species in order to test the impact of these mechanisms on the dynamics and persistence of the disease. Our results suggest that rabies persistence is sensitive to many of these factors and that the frequency and intensity of rabies outbreaks in the Arctic are likely driven by the interaction between these factors.

\section{Arctic fox mobility}

We hypothesized that the maintenance of rabies within the Arctic fox population required relatively high mobility of Arctic foxes (Hypothesis 1). Accordingly, we found that rabies was able to persist in high carrying capacity biotopes of the Arctic characterized by greater food 
resource abundance for foxes, such as human settlements or coastal habitats that provide stable food sources such as goose colonies (Lecomte et al. 2008; Norén et al. 2012), but required high transmission rates (i.e., a high mobility of Arctic foxes) to maintain epizootic cycles. Tyul'ko \& Kuzmin (2002) used a spatial model of rabies dynamics in the red fox population from a region with low carrying capacities similar to the Arctic tundra and found that rabies epizootics persisted only with high transmission rates consistent with those found in our study. However, transmission rate provides only an indirect measure of Arctic fox mobility, and further research using a spatially structured Arctic fox population would allow the effect of Arctic fox movements on rabies dynamics to be more directly assessed.

\section{Multi-annual prey cycles}

We hypothesized that multi-annual prey cycles exert a strong bottom-up effect on rabies dynamics and tested this by incorporating periodicity in the birth rate of foxes (Hypothesis 2). Our model suggests that the strong fluctuations in resource abundance that characterize Arctic ecosystems may impact rabies dynamics in a complex way. Indeed, incorporating Arctic fox population cycles in our model made rabies outbreaks less regular while increasing their intensity and decreasing their frequency. High-amplitude fluctuations in density of infectious Arctic foxes, resulting in high-intensity epizootics, are more likely to cause stochastic extinction of rabies, suggesting that, for Arctic fox populations undergoing intense demographic fluctuations, the local extinction of rabies is more likely as compared to other populations. Periodicities in rabies outbreaks reported in this study (2-11-year cycles) are comparable with the 6-10 year cycles reported by Mørk and Prestrud (2004) for Arctic fox populations in general. This variation may be related to observed differences in epizootics frequency/ intensity in areas where Arctic foxes are more or less dependent on lemmings as a prey base (Simon et al. in press). Interestingly, while rabies epizootics among fluctuating populations of Arctic foxes are thought to occur most often during periods of high population density (Mørk \& Prestrud 2004), the onset of simulated rabies epizootics in our study does not neatly track peaks in Arctic fox density, a result supported by observations of rabies in Arctic foxes at times of low population density (Rausch 1958).

\section{Incubation and infectious periods}

We hypothesized that prolonged incubation and infectious periods would increase rabies persistence
(Hypotheses 3 and 4). We found that rabies was able to persist across a large range of incubation periods. Since variation in incubation periods is one of the characteristics of rabies virus variants worldwide (WHO 2013), the impact of individual variation in incubation periods among infected Arctic foxes within a population may affect rabies dynamics in a more complex way. Our model showed that for a relatively low transmission rate of rabies, an incubation period longer than two months leads to extinction of rabies, even within a population at a relatively high density. However, for greater values of the transmission coefficient $\beta$, which indirectly reflects the mobility of Arctic foxes, rabies persisted for incubation periods of up to six months as reported in the literature (Rausch 1958; Mørk \& Prestrud 2004), suggesting that rabies persistence is favoured by longer incubation periods when efficient transmission is maintained within the population. An important characteristic of Arctic fox ecology that was not captured in our modelling approach is the ability of Arctic foxes to travel long distances during winter foraging movements (Mørk \& Prestrud 2004). Such long-distance movements may help maintain chains of infection by allowing efficient transmission within low-density Arctic fox populations.

Regarding Hypothesis 4, we found that infectious period exerted a strong influence on the cumulative density of rabies cases in Arctic foxes and that longer infectious periods than those reported in experimental studies (one to two days) (Konovalov et al. 1965; Rausch 1972) are required to maintain rabies even in high-density populations of Arctic foxes. In our model, the infectious period was limited to the symptomatic period, which can be very short in Arctic foxes; however, it is possible that infected Arctic foxes may begin to transmit rabies virus in their saliva before the onset of clinical illness, effectively prolonging the infectious period, as has been documented in other species including the red fox (Fekadu et al. 1982; Aubert 1992; Niezgoda et al. 1998).

\section{Immigration of infectious Arctic foxes and interaction with red foxes}

We hypothesized that immigration of infectious Arctic foxes is a mechanism that could allow rabies to continue circulating under conditions where the virus would not otherwise persist (Hypothesis 6). We incorporated high transmission rates, short incubation periods, prolonged infectious periods, periodicity in the birth rate, immigration and interaction with red foxes into our model to test their interacting effects and found that none of these mechanisms allowed the persistence of rabies 
in resource-poor areas of the Arctic characterized by Arctic fox densities of 0.15 Arctic foxes $/ \mathrm{km}^{2}$ and lower. In these low-density Arctic fox populations, immigration caused sporadic outbreaks of rabies, which is reflected by a strong correlation between the immigration rate of infectious Arctic foxes and cumulative density of rabies cases in sensitivity analysis. This result is consistent with empirical data from Svalbard, Norway, where episodic rabies cases in a relatively low-density Arctic fox population appear to be caused by the infrequent introduction of the virus by a small number of long-distant migrants coming from Russia (Mørk et al. 2011). This important potential role of immigration and long-distance movement in rabies dynamics and persistence in the Arctic suggests that metapopulation modelling or spatially explicit simulation approaches may be key avenues for future research.

We expected that the presence of sympatric red foxes would increase rabies persistence by increasing the overall density of susceptible individuals (Hypothesis 7). Our results suggest that the role of red foxes in Arctic rabies dynamics may depend on the relative abundance of red foxes and the stability of food resources. Where red foxes exist in low numbers in areas of variable food resources occupied by a cyclic Arctic fox population, their greater interaction with Arctic foxes may increase the intensity of epizootics, which also become more regular, whereas in a relatively stable environment (with no cyclicity in food resources), the presence of red foxes may have little impact on the intensity and frequency of epizootics in the Arctic fox population. These results underline an important potential public health consequence of the recent colonisation of Arctic ecosystems by low numbers of red foxes interacting with Arctic fox populations: more frequent interactions between the two fox species may lead to more intense rabies outbreaks. As the number of red foxes increases in the Arctic in regions characterized by variable food resources, their presence may increase the frequency of epizootics. These changes in the dynamics of Arctic rabies could have important consequences for the management of such outbreaks in northern villages, and the possible impact on the risk of rabies spillover to more southern latitudes. There is no clear evidence at this time that red foxes can serve as a reservoir of rabies in the absence of Arctic foxes. This is consistent with a recent molecular study in Alaska (Goldsmith et al. 2016), showing that circulation of the Arctic fox rabies virus variant in Alaska more closely aligns with the population structure of Arctic foxes than red foxes. This suggests that, for the time being, the dynamics of Arctic rabies depend more on the presence and density of Arctic foxes than red foxes.

\section{Impact of climate warming and northern development on rabies dynamics}

The impact of climate warming and northern development on the ecology and epidemiology of Arctic rabies has yet to be documented, but predictions of the response of Arctic ecosystems to such perturbations include fading rodent cycles, shrinking Arctic habitats (e.g., sea ice for winter foraging and movement) and red fox expansion (Fuglei \& Ims 2008; Kim et al. 2014). As shown in this study, these factors are associated with key mechanisms of rabies dynamics and persistence in the Arctic, that is, mobility and immigration of infectious Arctic foxes, interaction with red foxes and temporal variability in food resources. Our work suggests that fading of prey cycles may result in more stable rabies dynamics, while increasing interactions between Arctic and red foxes could intensify outbreaks initially where these species overlap. However, as red foxes gradually displace Arctic foxes and climate warming restricts winter movements due to reduced access to sea ice (modelled here as decreased carrying capacity and transmission rate, respectively), these ecological changes may ultimately limit rabies transmission in warmer areas, a scenario that is consistent with the study of Huettmann et al. (2017) predicting a reduction of the current ecological niche for detection of rabies virus in Alaska with climate warming.

\section{Conclusion}

Our study presents the unique nature of rabies ecology and epidemiology in the Arctic, identifying several important mechanisms that may allow rabies virus to persist in this extreme environment: high transmission rate, short and intermediate incubation periods, a prolonged infectious period and immigration of infectious Arctic foxes from other populations. Furthermore, the study highlights the need to better understand factors that influence the transmission rate of rabies among Arctic foxes and between Arctic and red foxes, as well as the immigration process in Arctic fox populations, which are potentially major drivers of rabies in the Arctic. Our study provides the first epidemiological demonstration that immigration may be a necessary mechanism for rabies occurrence in low-carrying capacity biotopes of the Arctic.

The deterministic two-species model developed in this study provides a first step towards a better understanding of Arctic rabies dynamics. Future studies are needed to explicitly incorporate key spatial processes underlying disease transmission, such as long-distance movements of Arctic foxes among spatially separated populations, and to explore the specific impacts of climate warming and northern development on rabies epidemiology. 


\section{Acknowledgements}

The authors thank Erin Rees and the reviewers for their excellent and helpful comments on earlier versions of the manuscript.

\section{Funding}

This study was supported by the Network of Centres of Excellence of Canada (ArcticNet), the Ministère de la Santé et des Services Sociaux du Québec, the Government of Newfoundland and Labrador, the Canada Research Chairs Program and the Natural Sciences and Engineering Research Council of Canada.

\section{Disclosure statement}

The authors report no conflict of interest.

\section{References}

Aenishaenslin C., Simon A., Forde T., Ravel A., Proulx J.F., Fehlner-Gardiner C., Picard I. \& Belanger D. 2014. Characterizing rabies epidemiology in remote Inuit communities in Quebec, Canada: a "one health" approach. Ecohealth 11, 343-355, http://dx.doi.org/10.1007/s10393-014-0923-1.

Altizer S., Dobson A., Hosseini P., Hudson P., Pascual M. \& Rohani P. 2006. Seasonality and the dynamics of infectious diseases. Ecology Letters 9, 467-484, http://dx.doi. org/10.1111/j.1461-0248.2005.00879.x.

Anderson R.M., Jackson H.C., May R.M. \& Smith A.M. 1981. Population dynamics of fox rabies in Europe. Nature 289, 765-771, http://dx.doi.org/10.1038/289765a0.

Angerbjörn A., Tannerfeldt M. \& Erlinge S. 1999. Predator-prey relationships: Arctic foxes and lemmings. Journal of Animal Ecology 68, 34-49, http://dx.doi.org/ 10.1046/j.1365-2656.1999.00258.x.

Aubert M.F. 1992. Epidemiology of fox rabies. In K. Bogel et al. (eds.): Wildlife rabies control. Pp. 9-18. Kent: Wells Medical Ltd.

Audet A.M., Robbins C.B. \& Lariviere S. 2002. Alopex lagopus. Mammalian Species 713, 1-10, http://dx.doi. org/10.1644/1545-1410(2002)713<0001:AL>2.0.CO;2.

Ballard W.B., Follmann E.H., Ritter D.G., Robards M.D. \& Cronin M.A. 2001. Rabies and canine distemper in an Arctic fox population in Alaska. Journal of Wildlife Diseases 37, 133-137, http://dx.doi.org/10.7589/0090-3558-37.1.133.

Blackwood J.C., Streicker D.G., Altizer S. \& Rohani P. 2013. Resolving the roles of immunity, pathogenesis, and immigration for rabies persistence in vampire bats. Proceedings of the National Academy of Sciences of the United States of America 110, 20837-20842, http://dx./doi.org/10.1073/ pnas.1308817110.

Blower S.M. \& Dowlatabadi H. 1994. Sensitivity and uncertainty analysis of complex models of disease transmission: an HIV model as an example. International Statistical Review 62, 229-243, http://dx.doi.org/10.2307/1403510.

Bolzoni L., De Leo G.A., Gatto M. \& Dobson A.P. 2008. Body-size scaling in an SEI model of wildlife diseases. Theoretical Population Biology 73, 374-382, http://dx.doi. org/10.1016/j.tpb.2007.12.003.

Carnell R. 2012. Package "lhs": Latin hypercube samples (version 0.14). Vienna: R Foundation for Statistical Computing. Accessed on the Internet at https://cran.r-project. org/web/packages/lhs/index.html.

CFIA (Canadian Food Inspection Agency) 2018. Rabies in Canada 2018. Accessed on the internet at http:// www.inspection.gc.ca/animals/terrestrial-animals/ diseases/reportable/rabies/rabies-in-canada/eng/ 1356156989919/1356157139999 on 13 March 2018.

Chapman R.C. 1978. Rabies: decimation of a wolf pack in Arctic Alaska. Science 201, 365-367, http://dx.doi.org/ $10.1126 /$ science. 566470 .

Dobson A. 2004. Population dynamics of pathogens with multiple host species. The American Naturalist 164 Supplement 5 , S64-S78, http://dx.doi.org/10.1086/424681.

Elmhagen B., Tannerfeldt M., Verucci P. \& Angerbjorn A. 2000. The Arctic fox (Alopex lagopus): an opportunistic specialist. Journal of Zoology 251, 139-149, http://dx.doi.org/ 10.1111/j.1469-7998.2000.tb00599.x.

Elton C. 1931. Epidemics among sledge dogs in the Canadian Arctic and their relation to disease in the Arctic fox. Canadian Journal of Research 58, 673-692, http://dx.doi. org/10.1139/cjr31-106.

Fekadu M., Shaddock J.H. \& Baer G.M. 1982. Excretion of rabies virus in the saliva of dogs. The Journal of Infectious Diseases 145 , 715-719, http://dx.doi.org/10.1093/infdis/145.2.715.

Follmann E.H., Ritter D.G. \& Baer G.M. 1988. Immunization of Arctic foxes (Alopex lagopus) with oral rabies vaccine. Journal of Wildlife Diseases 24, 477-483, http://dx.doi. org/10.7589/0090-3558-24.3.477.

Follmann E., Ritter D., Swor R., Dunbar M. \& Hueffer K. 2011. Preliminary evaluation of Raboral V-RG(R) oral rabies vaccine in Arctic foxes (Vulpes lagopus). Journal of Wildlife Diseases 47, 1032-1035, http://dx.doi. org/10.7589/0090-3558-47.4.1032.

Follmann E.H, Ritter D.G. \& Hartbauer D.W. 2004. Oral vaccination of captive Arctic foxes with lyophilized SAG2 rabies vaccine. Journal of Wildlife Diseases 40, 328-334, http://dx.doi.org/10.7589/0090-3558-40.2.328.

Fuglei E. \& Ims R.A. 2008. Global warming and effects on the Arctic fox. Science Progress 91, 175-191, http://dx.doi.org/ $10.3184 / 003685008 \times 327468$.

Gallant D., Slough B.G., Reid D.G. \& Berteaux D. 2012. Arctic fox versus red fox in the warming Arctic: four decades of den surveys in north Yukon. Polar Biology 35, 1421-1431, http://dx.doi.org/10.1007/s00300-012-1181-8.

Gilg O., Hanski I. \& Sittler B. 2003. Cyclic dynamics in a simple vertebrate predator-prey community. Science 302, 866-868, http://dx.doi.org/10.1126/science.1087509.

Goldsmith E.W., Renshaw B., Clement C.J., Himschoot E.A., Hundertmark K.J. \& Hueffer K. 2016. Population structure of two rabies hosts relative to the known distribution 
of rabies virus variants in Alaska. Molecular Ecology 25, 675-688, http://dx.doi.org/10.1111/mec.13509.

Henden J.-A., Ims R.A., Yoccoz N.G., Hellström P. \& Angerbjörn A. 2010. Strength of asymmetric competition between predators in food webs ruled by fluctuating prey: the case of foxes in tundra. Oikos 119, 27-34, http://dx.doi. org/10.1111/j.1600-0706.2009.17604.x.

Hersteinsson P. \& Macdonald D.W. 1992. Interspecific competition and the geographical distribution of red and Arctic foxes Vulpes-vulpes and Alopex-lagopus. Oikos 64, 505-515, http://dx.doi.org/10.2307/3545168.

Holmala K. \& Kauhala K. 2006. Ecology of wildlife rabies in Europe. Mammal Review 36, 17-36, http://dx.doi. org/10.1111/j.1365-2907.2006.00078.x.

Huettmann F., Magnuson E.E. \& Hueffer K. 2017. Ecological niche modeling of rabies in the changing Arctic of Alaska. Acta Veterinaria Scandinavica 59, 18-29, http://dx.doi. org/10.1186/s13028-017-0285-0.

Kim B.I., Blanton J.D., Gilbert A., Castrodale L., Hueffer K., Slate D. \& Rupprecht C.E. 2014. A conceptual model for the impact of climate change on fox rabies in Alaska, 1980-2010. Zoonoses and Public Health 61, 72-80, http://dx. doi.org/10.1111/zph.12044.

Knobel D.L., Cleaveland S., Coleman P.G., Fevre E.M., Meltzer M.I., Miranda M.E., Shaw A., Zinsstag J. \& Meslin F.X. 2005. Re-evaluating the burden of rabies in Africa and Asia. Bulletin of the World Health Organization 83, 360-368, http://dx.doi.org/10.1590/S0042-96862005000500012.

Konovalov G.V., Kantorovich R.A., Buzinov I.A. \& Riutova V.P. 1965. Experimental investigations into rage and rabies in polar foxes, natural hosts of the infection. II. An experimental morphological study of rabies in polar foxes. Acta Virologica 9, 235-239.

Krebs C.J. 2011. Of lemmings and snowshoe hares: the ecology of northern Canada. Proceedings of the Royal Society Biological Sciences Series B 278, 481-489, http://dx.doi. org/10.1098/rspb.2010.1992.

Lai S., Bety J. \& Berteaux D. 2015. Spatio-temporal hotspots of satellite-tracked Arctic foxes reveal a large detection range in a mammalian predator. Movement Ecology 3, article no. 37, http://dx.doi.org/10.1186/s40462-015-0065-2.

Lecomte N., Careau V., Gauthier G. \& Giroux J.F. 2008. Predator behaviour and predation risk in the heterogeneous Arctic environment. Journal of Animal Ecology 77, 439-447, http://dx.doi.org/10.1111/j.1365-2656.2008.01354.x.

Lembo T., Hampson K., Haydon D.T., Craft M., Dobson A., Dushoff J., Ernest E., Hoare R., Kaare M., Mlengeya T., Mentzel C. \& Cleaveland S. 2008. Exploring reservoir dynamics: a case study of rabies in the Serengeti ecosystem. Journal of Applied Ecology 45, 1246-1257, http://dx. doi.org/10.1111/j.1365-2664.2008.01468.x.

Mansfield K.L., Racloz V., McElhinney L.M., Marston D.A., Johnson N., Ronsholt L., Christensen L.S., Neuvonen E., Botvinicin A.D., Rupprecht C.E. \& Fooks A.R. 2006. Molecular epidemiological study of Arctic rabies virus isolates from Greenland and comparison with isolates from throughout the Arctic and Baltic regions. Virus Research 116, 1-10, http://dx.doi.org/10.1016/j.virusres.2005.08.007.
Marino S., Hogue I.B., Ray C.J. \& Kirschner D.E. 2008. A methodology for performing global uncertainty and sensitivity analysis in systems biology. Journal of Theoretical Biology 254, 178-196, http://dx.doi.org/10.1016/j.jtbi. 2008.04.011.

McCallum H., Barlow N. \& Hone J. 2001. How should pathogen transmission be modelled? Trends in Ecology $\theta$ Evolution 16, 295-300, http://dx.doi.org/10.1016/S0169-5347 (01) 02144-9.

Mørk T., Bohlin J., Fuglei E., Åsbakk K. \& Tryland M. 2011. Rabies in the Arctic fox population, Svalbard, Norway. Journal of Wildife Diseases 47, 945-957, http://dx.doi.org/ 10.7589/0090-3558-47.4.945.

Mørk T. \& Prestrud P. 2004. Arctic rabies-a review. Acta Veterinaria Scandinavica 45, 1-9, http://dx.doi.org/ 10.1186/1751-0147-45-1.

Morters M.K., Restif O., Hampson K., Cleaveland S., Wood J.L. \& Conlan A.J. 2013. Evidence-based control of canine rabies: a critical review of population density reduction. Journal of Animal Ecology 82, 6-14, http://dx.doi.org/ $10.1111 /$ j.1365-2656.2012.02033.x.

Nadin-Davis S.A., Sheen M. \& Wandeler A.I. 2012. Recent emergence of the Arctic rabies virus lineage. Virus Research 163, 352-362, http://dx.doi.org/10.1016/j. virusres.2011.10.026.

Niezgoda M., Briggs D.J., Shaddock J. \& Rupprecht C.E. 1998. Viral excretion in domestic ferrets (Mustela putorius furo) inoculated with a raccoon rabies isolate. American Journal of Veterinary Research 59, 1629-1632.

Norén K., Hersteinsson P., Samelius G., Eide N.E., Fuglei E., Elmhagen B., Dalen L., Meijer T. \& Angerbjörn A. 2012. From monogamy to complexity: social organization of Arctic foxes (Vulpes lagopus) in contrasting ecosystems. Canadian Journal of Zoology 90, 1102-1116, http://dx.doi. org/10.1139/z2012-077.

Pamperin N.J, Follmann E.H. \& Petersen B. 2006. Interspecific killing of an Arctic fox by a red fox at Prudhoe Bay, Alaska. Arctic 59, 361-364, http://dx.doi.org/10.14430/ $\operatorname{arctic} 284$.

Prager K.C., Mazet J.A., Dubovi E.J., Frank L.G., Munson L., Wagner A.P. \& Woodroffe R. 2012. Rabies virus and canine distemper virus in wild and domestic carnivores in northern Kenya: are domestic dogs the reservoir? Ecohealth 9, 483-498, http://dx.doi.org/10.1007/ s10393-013-0815-9.

Prestrud P., Krogsrud J. \& Gjertz I. 1992. The occurrence of rabies in the Svalbard islands of Norway. Journal of Wildife Diseases 28, 57-63, http://dx.doi.org/ 10.7589/0090-3558-28.1.57.

Pujol G., Iooss B. \& Janon A. 2017. Package "sensitivity": global sensitivity analysis of model outputs (version 1.15.0). Vienna: R Foundation for Statistical Computing. Accessed on the Internet at https://cran.r-project.org/web/ packages/sensitivity/index.html.

R Core Team 2017. R: a language and environment for statistical computing. Vienna: R Foundation for Statistical Computing. Accessed on the Internet at https:// www.R-project.org/. 
Rausch R.L. 1958. Some observations on rabies in Alaska, with special reference to wild canidae. Journal of Wildlife Management 22, 246-260, http://dx.doi.org/10.2307/3796457.

Rausch R.L. 1972. Observations on some natural-focal zoonoses in Alaska. Archives of Environmental Health 25, 246-252, http://dx.doi.org/10.1080/00039896.1972.106 66170.

Ritter D. 1981. Rabies. In R.A. Dieterich (ed.): Alaskan wildlife diseases. Pp. 6-12. Fairbanks: University of Alaska, Fairbanks.

Shirley M.D.F., Elmhagen B., Lurz P.W.W., Rushton S.P. \& Angerbjörn A. 2009. Modelling the spatial population dynamics of Arctic foxes: the effects of red foxes and microtine cycles. Canadian Journal of Zoology 87, 1170-1183, http://dx.doi.org/10.1139/Z09-104.

Simon A., Belanger D., Berteaux D., Hueffer K., Rees E. $\delta$ Leighton P.A. In press. Ecology of rabies in the Arctic fox (Vulpes lagopus). In D. Gregory \& R. Tinline (eds.):
Taking the bite out of rabies: the evolution of rabies management in Canada. Toronto: University of Toronto Press.

Soetaert K., Petzoldt T. \& Setzer RW. 2010. Solving differential equations in R: package deSolve. Journal of Statistical Software 33, 1-25, http://dx.doi.org/10.18637/jss. v033.i09.

Tyul'ko Z.S. \& Kuzmin I.V. 2002. Simulation of rabies epizootic process in fox populations at a limited carrying capacity of biotopes. Russian Journal of Ecology 33, 331-337, http://dx.doi.org/10.1023/A:1020265726669.

WHO 2013. World Health Organization expert consultation on rabies. Second report. WHO Technical Report Series 982. Geneva: World Health Organization.

Wu J., Dhingra R., Gambhir M. \& Remais J.V. 2013. Sensitivity analysis of infectious disease models: methods, advances and their application. Journal of The Royal Society Interface 10, article no. 20121018, http://dx.doi.org/10.1098/ rsif.2012.1018. 